Research article

\title{
Cost of resistance and tolerance under competition: the defense-stress benefit hypothesis
}

\author{
DAVID H. SIEMENS ${ }^{1,3, *, \dagger}$, HEIKE LISCHKE ${ }^{2}$, NICOLE MAGGIULLI ${ }^{3}$, \\ STÉPHANIE SCHÜRCH ${ }^{1}$ and BITTY A. ROY ${ }^{1,3}$ \\ ${ }^{1}$ Swiss Federal Institute of Technology (ETH), Geobotanical Institute, Zürichbergstr. 38, 8044 \\ Zürich, Switzerland; ${ }^{2}$ Landscape inventories, WSL Swiss Federal Research Institute, Zürcherstr. 111, \\ CH-8903 Birmensdorf; ${ }^{3}$ Center for Ecology and Evolutionary Biology, 5289 Biology Department, \\ University of Oregon, Eugene, OR 97403-5289; USA; \\ ${ }^{\dagger}$ Present address: Biology Department, Black Hills State University, 1200 University St., Spearfish, \\ SD 57799, USA \\ (*author for correspondence,e-mail: davidsiemens@bhsu.edu)
}

Received 9 September 2002; accepted 10 June 2003

Co-ordinating editor: J. Tuomi

\begin{abstract}
Defense costs provide a major explanation for why plants in nature have not evolved to be better defended against pathogens and herbivores; however, evidence for defense costs is often lacking. Plants defend by deploying resistance traits that reduce damage, and tolerance traits that reduce the fitness effects of damage. We first tested the defense-stress cost (DSC) hypothesis that costs of defenses increase and become important under competitive stress. In a greenhouse experiment, uniparental maternal families of the host plant Arabis perennans were grown in the presence and absence of the bunch grass Bouteloua gracilis and the herbivore Plutella xylostella. Costs of resistance and tolerance manifest as reduced growth in the absence of herbivory were significant when $A$. perennans grew alone, but not in the competitive environment, in contrast to the DSC hypothesis. We then tested the defense-stress benefit (DSB) hypothesis that plant defenses may benefit plants in competitive situations thereby reducing net costs. For example, chemical resistance agents and tolerance may also have functions in competitive interactions. To test the DSB hypothesis, we compared differentially competitive populations for defense costs, assuming that poorer competitors from less dense habitats were less likely to have evolved defenses that also function in competition. Without competitive benefits of defenses, poorer competitors were expected to have higher net costs of defenses under competition in accordance with DSB. Populations of $A$. perennans and $A$. drummondii that differed dramatically in competitiveness were compared for costs, and as the DSB hypothesis predicts, only the poor competitor population showed costs of resistance under competition. However, cost of tolerance under competition did not differ among populations, suggesting that the poor competitors might have evolved a general stress tolerance. Although the DSC hypothesis may explain cases where defense costs increase under stress, the DSB hypothesis may explain some cases where costs decrease under competitive stress.
\end{abstract}

Key words: Arabis drummondii, Arabis perennans, Bouteloua gracilis, competition, costs, Plutella xylostella, resistance, stress, tolerance 


\section{Introduction}

Cost/benefit optimization hypotheses are fundamental in evolutionary ecology (Orzack and Sober, 2001). Various kinds of costs or constraints may be associated with the production of plant defenses against herbivores and pathogens (Simms, 1992; Berenbaum and Zangerl, 1999; Pilson, 2000; Purrington, 2000) providing one of the major explanations for why defense traits have not become fixed within populations (Simms and Rausher, 1987). Although some evidence for defense costs exists, many studies have not detected costs (Simms, 1992; Bergelson and Purrington, 1996; Rausher, 1996; Karban and Baldwin, 1997; Strauss et al., 1999; Strauss et al., 2002). Aside from the technical difficulties of studying defense costs, this lack of consistent costs calls into question the general importance of costs, or it may also be that other ecological factors dictate the magnitude, and thus our ability to detect these costs.

We tested two hypotheses regarding the effects of ecological stress on the detectability and importance of defenses costs. We did this for the two basic types of defenses that plants deploy, resistance and tolerance. First, we tested the hypothesis that costs of these defenses increase, and therefore become important, in more stressful environments (Bergelson, 1994b; Bergelson and Purrington, 1996; Weis and Hochberg, 2000). Defense costs are generally thought of as a reduction in relative growth or reproduction in defended populations in the absence of pests (Simms and Rauscher, 1992; Berenbaum and Zangerl, 1999). Stressful environments for plants are often associated with decreases in resources, such as soil nutrients, water, space, and light. If plants maintain defense levels as resources decline, then growth and other competing physiological processes may decrease, in accordance with optimal allocation theory for plant defense (McKey, 1974; Rhoades, 1979; Zangerl and Bazzaz, 1992; Bazzaz and Grace, 1997; Hamilton et al., 2001). Hereafter we refer to this as the 'defense-stress cost' (DSC) hypothesis. Some recent studies (e.g., Siemens et al., 2002), however, have found that costs of defenses may sometimes decrease under competitive stress. This has led to an alternative hypothesis that there may be benefits associated with defenses under competition, thereby reducing net defense costs (Siemens et al., 2002). We refer to this as the 'defensestress benefit' (DSB) hypothesis.

The DSC and DSB hypotheses were formulated for costs of resistance traits, but plants also deploy tolerance and avoidance against attack (Berrymann, 1988; Strauss and Agrawal, 1999; Tiffin, 1999; Roy and Kirchner, 2000; Stowe et al., 2000). Like resistance, these other traits may also be evolutionary responses to attack, and therefore are often referred to as defenses (e.g., Mauricio et al., 1997). While resistance and avoidance traits function to reduce herbivory, tolerance traits function after damage to reduce the impact of herbivory on host growth and reproduction. Although some empirical studies have begun 
to investigate the effects of stressful environments on costs of resistance (Williams et al., 1995; Bergelson et al., 1996; Augner et al., 1997; van Dam and Baldwin, 1998; Siemens et al., 2002) even fewer have examined the effects of environmental stress on costs of tolerance (Hochwender et al., 2000). We examined the effects of competitive stress on costs of resistance and tolerance, and on the putative trade-off between these defense responses (Fineblum and Rausher, 1995; Stowe, 1998; Mauricio, 2000; Roy and Kirchner, 2000) to test the DSC hypothesis. We then tested the DSB hypothesis to explain our findings that defense costs became undetectable under competition.

We studied costs of defenses in two species of rock cress (Brassicaceae) Arabis perennans and A. drummondii. Species of Arabis are well suited for ecological genetic studies because they are small, short lived species that are readily grown from seed in large numbers needed for evolutionary experiments. Moreover, species of Arabis are among the closest wild relatives of Arabidopsis thaliana and therefore offer great potential for future studies in molecular ecology (Koch et al., 2000; Pennisi, 2000; Mitchell-Olds, 2001). To test the DSC hypothesis we grew uniparental maternal families of $A$. perennans in the presence and absence of a common native bunch grass Bouteloua gracilis and an enemy: diamondback moth larvae Plutella xylostella. To test the DSB hypothesis we conducted a similar experiment using families of $A$. perennans and $A$. drummondii from habitats that differed dramatically in the density of potential competitors and in correlated competitiveness. We reasoned that poor competitors are less likely to have evolved defenses that also function in competition, and therefore should show defense costs under competition.

\section{Methods}

\section{Experimental organisms}

Arabis perennans S. Wats. and A. drummondii A. Gray grow in diverse mountainous habitats mainly in western North America (Rollins, 1993). In the Southwest, A. perennans can be found in moderately dense bunch grass communities in the understory of mixed pine, juniper, and oak woodlands, while A. drummondii is often found in very dense grassy subalpine meadows. We have also found A. perennans growing in the cinder fields of Sunset Crater National Monument near Flagstaff, Arizona, where understory competitors are essentially absent. Competitiveness of these Arabis against the bunch grass Bouteloua gracilis reflected the density of potential competitors in their native habitats (see Results) and we used this genetic variation in competitiveness to 
test the DSB hypothesis (see below under DSB Experiment). The bunch grass B. gracilis is distributed throughout North America (Hitchcock, 1951) and commonly found growing with Arabis species.

The diamondback moth Plutella xylostella is a specialist herbivore on brassicaceous plants, and elicits induced defense responses in several species, such as Brassica rapa (Siemens and Mitchell-Olds, 1996; 1998; Siemens et al., 2002) and Arabidopsis thaliana (Stotz et al., 1999; Stotz et al., 2000). Because $P$. xylostella is easily cultured and manipulated for experimentation, we used P. xylostella to elicit induced responses in Arabis that otherwise might not occur with just artificial wounding (Baldwin, 1990; Tiffin and Inouye, 2000). We used larvae from a laboratory colony originally collected in Geneva, New York by A. Shelton in 1988 and maintained on artificial diet, which does not affect larval physiology even after several generations on the diet (Shelton et al., 1990).

\section{Detecting costs}

To detect costs of resistance and tolerance we regressed family mean growth rates of undamaged controls against defense levels. While resistance was estimated from measures of leaf area consumed, for costs of tolerance, growth rates of controls were regressed against growth of damaged plants, which is an unbiased test of a cost of tolerance (Strauss and Agrawal, 1999). Estimates of costs of tolerance were not affected by a cost of resistance (Strauss and Agrawal, 1999; Stowe et al., 2000) since we removed proportionately the same leaf area from each plant in our clipping treatments (see below). The tolerance costs we report were also found for plots of undamaged growth against tolerance, where tolerance is the reaction norm (slope) of growth across damage treatments (Simms, 2000), and where undamaged controls were not also used to compute tolerances (Stowe et al., 2000). Further, we make the assumption that growth of controls (vigor or intrinsic growth rates) does not influence tolerance through simple rules of growth (Stowe et al., 2000). Although this may not always be the case, recent simulations suggest that this may be approximately correct for most cases (Weis et al., 2000).

\section{DSC experiment}

Seeds from 48 maternal families of $A$. perennans were planted in the presence and absence of the herbivore $P$. xylostella and the competitor B. gracilis using a split-plot experimental design. Herbivory and competition treatments were completely crossed at the whole-plot level, and maternal families of $A$. pe- 
rennans were randomized within plots. For practical reasons, competition and herbivory were varied among flats in the greenhouse to prevent competitive effects (e.g., shading, allelopathy) and herbivory on control plants. Statistically, the split-plot design is relatively powerful for detecting genotype-by-environment interactions, which are needed to detect genetic variation in tolerance (see below).

Seeds from 48 individual $A$. perennans plants (maternal families) for this experiment were collected at several sites in Northern Arizona and Southern Utah: (1) Pine Crest and Switzer Canyon in Flagstaff, Coconino Co., Ariz., (2) Anderson Mesa near Upper Lake Mary, $29 \mathrm{~km} \mathrm{~S}$ of Flagstaff, (3) collection no. 9972 , $37^{\circ} 27^{\prime} 22^{\prime \prime} \mathrm{N} / 112^{\circ} 33^{\prime} 40^{\prime \prime} \mathrm{W}$, Kane, Co., Utah, (4) collection no. 9976, $37^{\circ} 46^{\prime} 28^{\prime \prime} \mathrm{N} / 112^{\circ} 46^{\prime} 40^{\prime \prime} \mathrm{W}$ Garfield, Co., Utah, and (5) collection no. 9942, N. Rim Grand Canyon, $36^{\circ} 43^{\prime} 57^{\prime \prime} \mathrm{N} / 112^{\circ} 06^{\prime} 04^{\prime \prime} \mathrm{W}$, Coconino, Co., Ariz. Collection numbers for sites 3, 4, and 5 are reference numbers used in the Arabis seed collection at the Max Planck Institute of Chemical Ecology, Jena, Germany, where there are also voucher specimens. We used seeds from 10 families collected from site 1, 23 from site 2, and five from each of sites 3, 4, and 5, reflecting the abundance of families collected at each site. We used families collected over a wide geographic range to increase genetic diversity and thus statistical power, although this limits our ability somewhat to draw inferences about evolutionary processes occurring within populations (Weis and Campbell, 1991). Some collections, especially at sites 3, 4, and 5 may even have included individuals introgressed with very similar A. holboellii or A. fendleri (Rollins, 1993).

The uniparental breeding systems of these populations probably includes apomixis and some sexual reproduction with rare outcrossing (Roy, 1995). Thus, siblings within families were the same or very similar genetically, which is ideal for measures of tolerance, the reaction norm of fitness across damage gradients (Simms, 2000). On the other hand, because apomixis (asex by seed) links the entire genome, costs attributed to defenses may instead be caused by other unmeasured correlated traits. However, we found the same results as we have for the sexual species B. rapa (Siemens et al., 2002): competition has not increased costs of resistance in these brassicaceous species.

Seeds from each of the 48 families were randomized within each of 18 flats, for a total sample size of 864 . Flats were trays containing 48 pots, and a flat represented a plot in the experimental design. Flats were rotated $180^{\circ}$ and moved to an adjacent location in the greenhouse every $4 \mathrm{D}$ to further even out environmental effects. Plants were grown under light banks $(16 \mathrm{~h} \mathrm{~L}, 8 \mathrm{~h} \mathrm{D}$, 50 klux lamps) in a glass house with temperatures ranging between $22-24{ }^{\circ} \mathrm{C} \mathrm{D}$ and $17-19^{\circ} \mathrm{C} \mathrm{N}$. Two seeds of $A$. perennans were planted in each $0.3 \mathrm{~L}$ pot filled with $1 / 3$ each of potting soil, perlite, and sand, and culled to one plant within a few days of germination. Germination rates are typically $>80 \%$ after 
a 2-week vernalization period at 4 or $5{ }^{\circ} \mathrm{C}$. At the time we planted $A$. perennans, we also sowed $B$. gracilis seed around the $A$. perennans seeds within each pot, resulting in $2.9 \pm 0.06$ (mean $\pm 1 \mathrm{SE}$ ) B. gracilis plants per pot for the competition treatment. Three weeks after germination, $B$. gracilis was thinned to no more than two plants per pot to prevent competitive effects from becoming too strong. We used seeds of B. gracilis collected in bulk between Flagstaff and Sedona, Ariz. by the Arizona Seed Co., Flagstaff.

At approximately weekly intervals throughout the experiment we measured the greatest rosette diameter of the A. perennans plants, then at the end of 11 weeks, shoots were harvested for biomass. Diameter of basal rosettes and correlated growth rates $(r=0.86, p<0.001)$ and biomass $(r=0.37-0.62$ depending on time, $p<0.001$ ) of shoots can be important components of fitness in the evolution of plant competition (Miller, 1995) and tolerance to herbivory (Hochwender et al., 2000; Weis et al., 2000). Moreover, rosette diameter of reproductive individuals in natural populations is at least weakly correlated with fruit production $(r=0.47, p<0.001)$, and number of fruits is positively correlated with seed number $(r=0.71, p<0.05)$ and weight per seed $(r=0.75, p<0.05)$. Unfortunately, it was not feasible to run this experiment to seed production.

We placed $P$. xylostella larvae on plants to induce defenses and to measure plant resistance. Four weeks after germination, one first instar larva of P. xylostella was placed on each A. perennans plant in half the flats within each competition treatment. We used larvae that had hatched and fed a few hours on artificial diet, which minimized larval mortality when placed on foliage. Larvae were allowed to feed for approximately $24 \mathrm{~h}$ on $A$. perennans, then larvae were removed and herbivory recorded. We recorded leaf area consumed and the leaves where feeding occurred. We used a transparent grid with $1-\mathrm{mm}^{2}$ squares, and estimated leaf area consumed to the nearest tenth of a grid under a dissecting microscope. Larvae were placed on mature leaves between the center and outer edge of the rosette, but larvae also fed on young leaves in the center of the rosette and older senescing leaves at the outer edge of rosettes. Hence, for each plant we recorded leaf area consumed from young, mature, and senescing leaves. Our measure of herbivory for analysis was leaf area consumed from mature leaves.

Three days after larvae were first placed on plants, we removed $1 / 3$ of the leaves from each plant fed upon to increase the impact of herbivory on A. perennans growth rates and to make the percentage of leaf area 'consumed' uniform in the damage treatment. A uniform damage treatment eliminated the confounding effects of costs of resistance when estimating tolerance to damage (Stowe et al., 2000). We counted the number of leaves per plant, and then cut off the middle $1 / 3$ of leaves at the petioles with a pair of scissors. 
DSB experiment

The design of this experiment was essentially the same as described above for the DSC experiment, however, we used maternal families of $A$. perennans from site 2 (the Lake Mary site), from Sunset Crater, and families of $A$. drummondii collected near the Rocky Mountain Biological Lab, Crested Butte, Colorado. We planted three replicates of 14 families from each Arabis population in 32 plots for 4032 plants total. The uniparental breeding system of $A$. drummondii is sexual and highly selfing (Roy, 1995). In addition to competition and herbivory treatments, we added another whole-plot factor of fertilizer $(66 \mathrm{mg}$ 14:14:14 NPK per pot plus micronutrients) in attempt to eliminate nutrient stress in the control treatments, as we used relatively nutrient poor peatmoss instead of potting soil. Fertilizer did not affect the patterns of interest. Also larvae in this experiment were confined to feeding on a single leaf with plastic clip cages.

\section{Statistical analysis}

We used mixed-model ANCOVA with Type III sums of squares in SYSTAT version 6.0 to analyze the data in our split-plot experiments. We considered the whole-flat factors of competition and damage as fixed effects, family as a random within-flat effect, and flat as a random effect nested within the wholeplot factors. ANCOVA on family means was conducted to test for costs of tolerance and resistance. In these tests, flat does not appear in the analysis. The split-plot analysis was used to test for significance in genetic variation in tolerance to damage and resistance to herbivory. The response variable in tests for tolerance or competitiveness included rosette diameter and growth rate, and statistically significant genetic variation was indicated by a damage- or competition-by-family interaction for tolerance to herbivory or competitiveness respectively (Tiffin and Rausher, 1999). We also conducted repeated measures ANCOVA when using rosette diameters and growth rates as the response variables. We computed F-ratios from appropriate mean-square errors for this split-plot design (Zar, 1996). Preliminary inspection of the data for the interaction between family and any unmeasured whole-flat factors (family by-flat nested within competition and damage) determined that this interaction was not important; therefore this interaction was not included in the analyses (Montgomery, 1997). Eliminating this interaction simplified the analyses and did not affect the main results.

The first measure of rosette diameter was used as a covariate in analyses to control for any correlated maternal or developmental effects such as time of germination and seed size (Siemens and Mitchell-Olds, 1998; Siemens et al., 2002). Running the analyses with interaction terms for the covariate did not 
result in any significant interactions with main effects (tests for homogeneity of slopes, $p s>0.1$ ), therefore this covariate does not appear in interaction terms in our analyses. When the covariate did not affect the results and was not statistically significant, then the covariate was left out of analyses entirely.

The DSC experiment was not designed to include the sites of $A$. perennans seed origin in the statistical analyses because replication within sites was highly unbalanced. Instead, after analyses of families for genetic variation and covariation were completed, we examined the patterns visually for variation among sites. Although variation among sites contributed to the resulting patterns, all of the general patterns reported in this paper were observed within most sites. However, further studies would be needed to distinguish genetic variation within and among populations of $A$. perennans.

\section{Results}

\section{DSC experiment}

We detected a significant allocation cost of resistance; families that were eaten less grew slower in the absence of herbivores, but this cost of resistance was only evident when $A$. perennans grew alone (competition-by-herbivory interaction: $F_{1,58}=8.86, p=0.004$ ) in contrast to the DSC hypothesis (Fig. 1a). However, this cost was transitory, as it was only detected in the 2-week period immediately following the damage treatments, and not in the 2 week period before damage or in the last week of the experiment (time-by-competition-byherbivory interaction in the within subjects repeated measures ANCOVA: $F_{2,116}=6.66, p=0.002$ ).

A significant cost of tolerance to damage was also detected, and just as for resistance, this cost was only evident when $A$. perennans grew alone (Fig. 1b). Families that grew relatively fast when damaged had lower growth rates when undamaged, but this cost of tolerance was not detected in the competitive environment (competition-by-damaged growth interaction: $F_{1,94}=21.06$, $p=0.005)$. These analyses were conducted using undamaged growth rates in the period preceding damage, but similar patterns were also evident for analyses with undamaged growth rates following damage (competition-by-damaged growth interaction, $F_{1,89}=4.03, p=0.048$ ).

Another potentially important effect of competition for the evolution of defense was the effect on genetic variation of defense. Genetic variation in resistance against herbivory depended on the competition treatment (competition-by-family interaction for leaf area consumed, Table 1). Competition increased resistance in some families, decreased it in others, and in some families there was no effect. We also found significant genetic variation in 

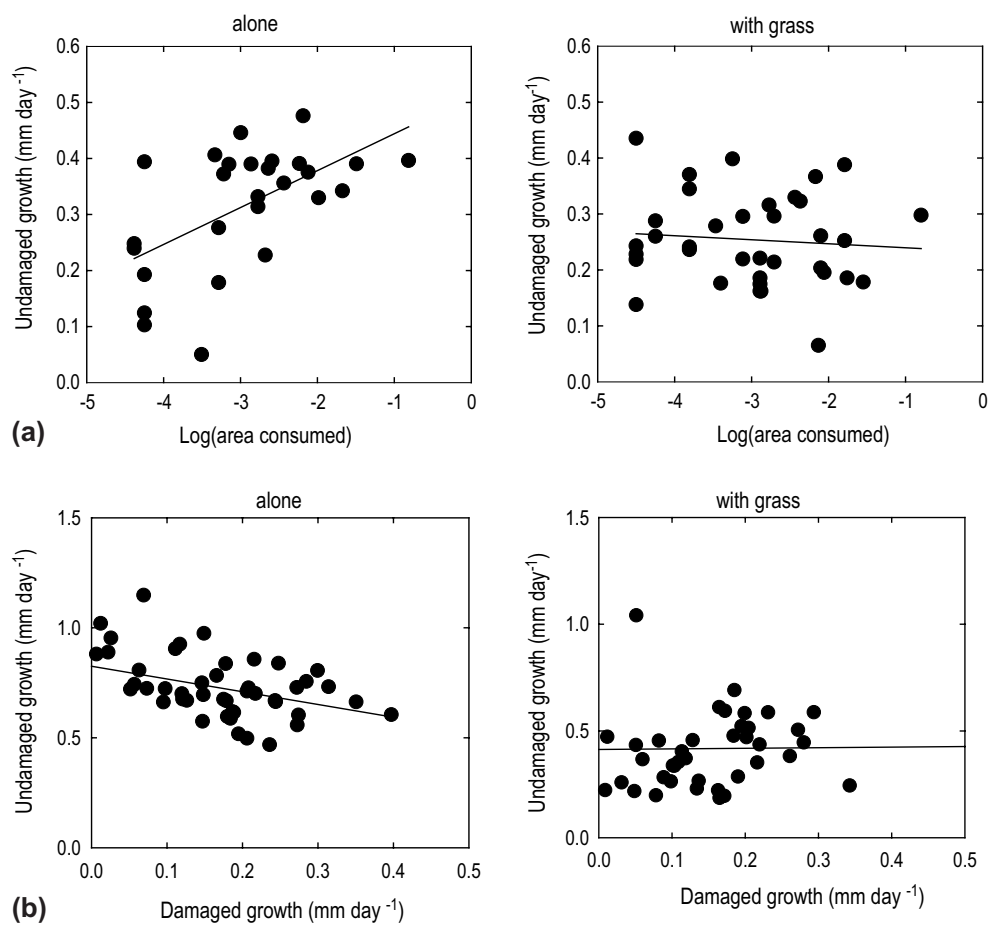

Figure 1. Cost of (a) resistance and (b) tolerance across competitive environments.

Table 1. Split-plot analysis for genetic variation in herbivory on A. perennans

\begin{tabular}{lrrrl}
\hline Source $^{\mathrm{a}}$ & \multicolumn{1}{l}{ Df } & \multicolumn{1}{l}{ MS } & \multicolumn{1}{l}{$F$} & \multicolumn{1}{l}{$l$} \\
\hline Competition & 1,48 & 3.618 & 2.398 & 0.128 \\
Family & 48 & 0.969 & 0.994 & 0.492 \\
Comp*family $^{\text {Leaf age }}$ & 48 & 1.508 & 1.547 & 0.021 \\
Rosette diam $_{\text {Error }}^{2}$ & 1 & 134.466 & 137.889 & 0.000 \\
& 194 & 0.008 & 0.009 & 0.926 \\
\hline
\end{tabular}

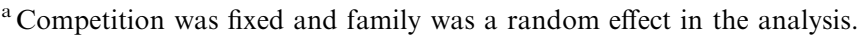

${ }^{\mathrm{b}}$ In addition to rosette diameter, leaf age (young, mature, and senescing) was used as a covariate in the analysis. The covariates either did not interact with other factors, or there were insufficient degrees of freedom for these tests, therefore interactions with the covariates were not included in the model.

tolerance to damage (damage-by-family interaction, Table 2), and tolerance levels of families grown in isolation were not correlated with tolerance levels under competition $\left(r=0.19, \mathrm{df}=1, \chi^{2}=1.7, p=0.20\right)$. Further evidence that tolerance levels were affected by competition was a significant interaction among family, damage, and competition $\left(F_{143,487}=1.32, p=0.015\right)$ in a full 
Table 2. Split-plot analysis on undamaged growth to detect genetic variation in tolerance to herbivory (family by-damage interaction)

\begin{tabular}{lrrrr}
\hline Source $^{\mathrm{a}}$ & \multicolumn{1}{l}{ Df } & \multicolumn{1}{c}{ MS } & \multicolumn{1}{l}{ F } \\
\hline Damage & $1,6.47$ & 16.166 & 0.190 & 0.673 \\
Family & 47 & 6.979 & 1.179 & 0.215 \\
Damage*family $^{\mathrm{b}}$ & 47 & 9.167 & 1.549 & 0.019 \\
Flat(Damage) $_{\text {Rosette diameter }}$ & 6 & 82.114 & 13.872 & 0.000 \\
Error & 2 & 66.957 & 11.312 & 0.000 \\
\hline
\end{tabular}

${ }^{\text {a }}$ Split-plot design. Damage was a fixed whole-flat factor, family was random within flats, flat was random and nested within competition. $F$-ratios and df according to Zar (1996). All factors except damage were tested over $\mathrm{MS}_{\mathrm{E}}$. Denominator for damage $F$-ratio $=\left(\mathrm{MS}_{\mathrm{D}^{*} \mathrm{~F}}+\mathrm{MS}_{\mathrm{F}(\mathrm{D})}-\mathrm{MS}_{\mathrm{E}}\right)$, where $\mathrm{D} * \mathrm{~F}=$ Damage*Family, $\mathrm{F}=$ Flat(Damage), and $\mathrm{E}=$ Error.

${ }^{\mathrm{b}}$ This analysis was conducted on plants in the absence of competition, but a significant interaction was also detected under competition $\left(F_{47,255}=1.623, p=0.010\right)$.

Table 3. Regression of tolerance to damage (slope of growth across damage treatments) on competitiveness and herbivory

\begin{tabular}{lllll}
\hline Source $^{\mathrm{a}}$ & Df & MS & $F$ & $p$ \\
\hline Competitiveness & $2^{\mathrm{b}}, 2$ & 0.960 & 1.050 & 0.488 \\
Herbivory & $2^{\mathrm{b}}, 2$ & 0.925 & 1.012 & 0.497 \\
Competitiveness*herbivory & $2^{\mathrm{b}}$ & 0.914 & 3.756 & 0.042 \\
Error & 19 & 0.243 & & \\
\hline
\end{tabular}

Herbivory and tolerance to damage were measured in the absence of competition; the same relationships did not hold for measures of herbivory and tolerance to damage under competition. ${ }^{a}$ Both factors were random effects, thus each was tested over the interaction MS.

${ }^{\mathrm{b}}$ Linear and quadratic terms included, hence $2 \mathrm{df}$.

model analysis. As for resistance, the rank order of families changed across competition treatments (not shown).

We also detected a significant $(p=0.042)$ genetic correlation between resistance and tolerance, which was only evident in the absence of competition; however, the correlation was mainly positive and weak (Table 3). Moreover, this result was contingent on family competitiveness, measured as the slope of intrinsic growth across competition treatments.

\section{$D S B$ experiment}

As predicted, the only evidence for costs of resistance under competition came from the population that was the poorest competitor (Figs. 2, 3). Although the difference between the most- and least-competitive Arabis in the dynamics of costs across competition treatments (Fig. 2) was only marginally significant (population-by-competition-by-herbivory interaction: $F_{1,36}=3.06, p=0.089$ ), 

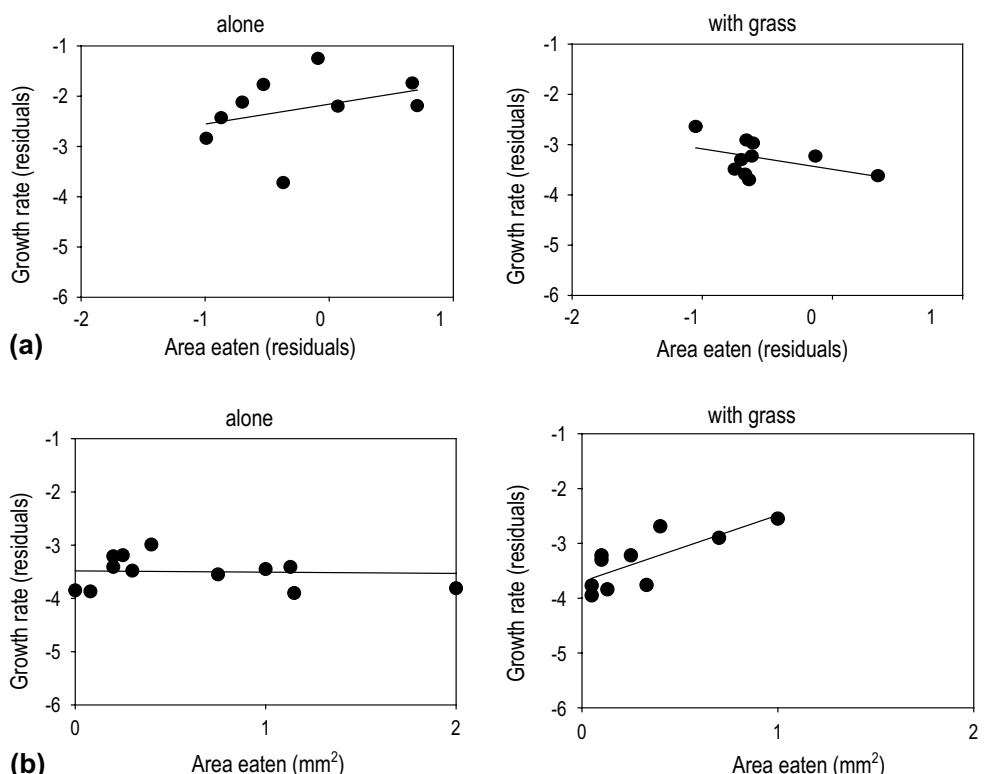

Figure 2. Cost of resistance for (a) competitive A. drummondii and (b) less competitive A.perennans (from Sunset Crater) across competitive environments. Competitive and less-competitive refer to relative growth rates when grown against the grass B. gracilis (Fig. 3). Residuals controlled for plot and developmental effects when significant. Cost of resistance under competition in the Sunset Crater population was also evident in the fertilized plants (not shown).

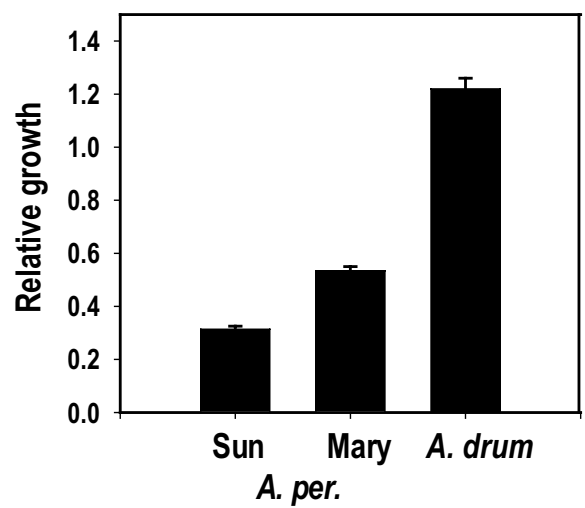

Figure 3. Differences in competitiveness (relative growth $=$ growth rate next to the grass competitor $B$. gracilis/growth rate when alone) among the A. perennans populations and $A$. drummondii. Error bars are $1 \mathrm{SE}$ computed for ratios. All differences were considered significant as $\gg 2 \mathrm{SE}$ separate the means.

the patterns were essentially those that we predicted. Costs increased under competition only for the Sunset Crater population of A. perennans 

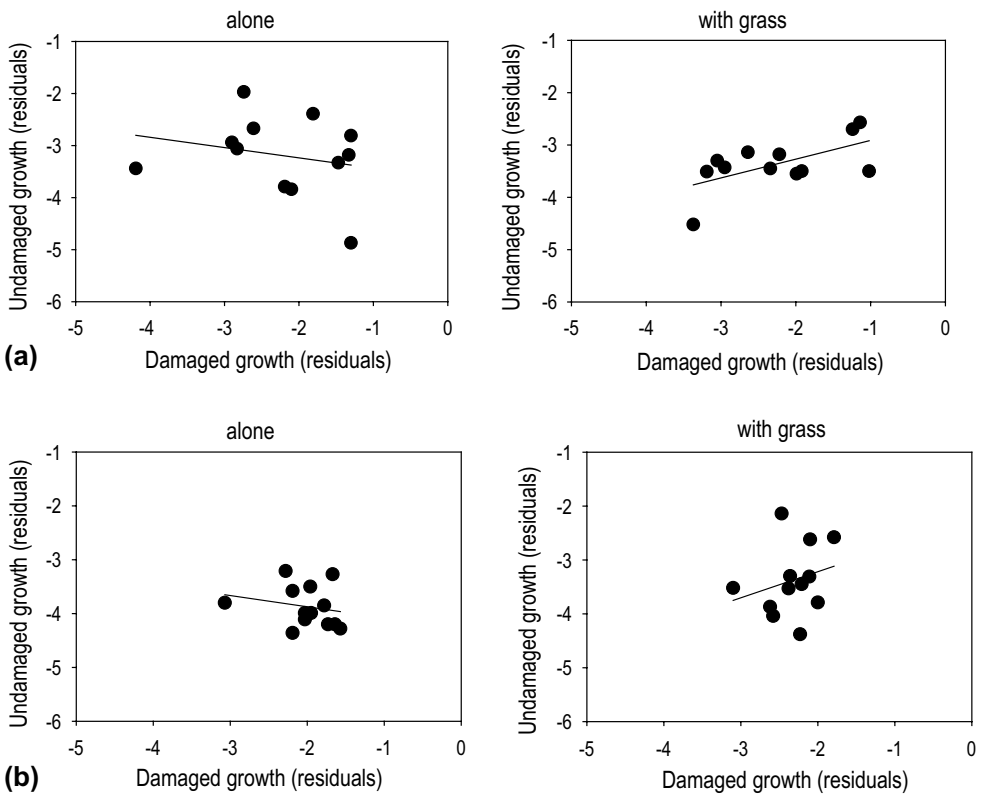

Figure 4. Cost of tolerance for (a) competitive A. drummondii and (b) less competitive A.perennans (from Sunset Crater) across competitive environments. Competitive and less-competitive refer to relative growth rates when grown against the grass $B$. gracilis (Fig. 3). Residuals controled for plot and developmental effects when significant. Fertilized plants (not shown) also did not show costs under competition.

(competition-by-herbivory interaction: $F_{1,19}=12.64, p=0.002$ ), which was also the least competitive population (Fig. 3) as expected based on the absence of potential understory competitors at this site.

There was no difference among populations in the dynamics of tolerance costs across competition treatments (Fig. 4). As in the DSC experiment, costs of tolerance that were observed when plants grew alone were not evident in the competitive environment (competition-by-growth interaction: $F_{1,45}=5.80$, $p=0.020)$.

\section{Discussion}

Although evidence for costs of plant defenses exists, little is known about the dynamics of costs across important ecological gradients (Purrington, 2000). We first tested the DSC hypothesis, which predicts that costs of host plant defenses should increase when plants grow next to non-host neighbors in competitive situations (Bergelson, 1994b; Bergelson and Purrington, 1996; 
Weis and Hochberg, 2000). In contrast to the DSC hypothesis, we found that costs of tolerance and resistance that were evident when plants grew alone were not detectable in the competitive environment. In their review on costs of plant resistance against herbivores, pathogens, and herbicides, Bergelson and Purrington (1996) cited only four studies that had tested for the effects of stressful environments on costs. They concluded that no discernable pattern had yet emerged to evaluate the general prediction that costs of defenses should increase in stressful environments. Of 19 cases we know of that have tested the effects of competition and/or limited resources on costs of resistance, including the present study, six have shown a decrease (Darmency and Pérnes, 1989; Reboud and Till-Bottraud, 1991; Augner et al., 1997; Baldwin and Hamilton, 2000; Siemens et al., 2002), seven no change (Bergelson, 1994b; Purrington and Bergelson, 1997; van Dam and Baldwin, 1998; Jordan, 1999; Siemens et al., 2002), and six have shown an increase (Reboud and Till-Bottraud, 1991; Bergelson, 1994a; Williams et al., 1995; Purrington and Bergelson, 1997; Baldwin and Hamilton, 2000). Of the two cases we know of that have tested the effects of competition or limited resources on costs of tolerance, one showed an increase (Hochwender et al., 2000) and ours has shown a decrease. Despite this apparent lack of empirical support for the DSC hypothesis, several subsequent theoretical studies on costs and benefits of plant defenses have made the major assumption that costs of defenses increase under competitive stress (Jaremo et al., 1996; Adler, 1999; Weis and Hochberg, 2000). Clearly, studies are needed that test alternative hypotheses for the dynamics of defense costs across stressful ecological gradients.

Second, to explain our result that costs of defenses became undetectable in the competitive environment, we tested the DSB hypothesis, which states that defenses may have duel functions in competition to reduce net defense costs under competition. Our test was to compare host plant populations that had apparently evolved to be differentially competitive, with the assumption that less competitive populations would be less likely to have evolved defenses that also function in plant-plant interactions. Without competitive benefits from defenses, we predicted that a less competitive population should exhibit defense costs in a competitive environment. Our results supported this prediction of the DSB hypothesis for costs of resistance but not tolerance. One explanation for these results is that growth rules produced the apparent costs of tolerance (Weis et al., 2000), which did not differ between populations. Although we cannot dismiss this possibility, our explanation is that tolerance served a competitive function in all populations to reduce net costs. Tolerance to herbivory may overlap with general ability to tolerate physiological stress.

Whether the Arabis populations that differed in competitiveness also differed in allelopathic effects that were genetically correlated with resistance is unkown. 
Very few empirical studies have even reported on the evolution of resource competition or allelopathy (Callaway and Aschehoug, 2000). However, secondary metabolites can serve duel functions in defense and competition (Inderjit, 1996), which may affect defense costs. Moreover, a theoretical model that predicts an amplification of defense costs under competition (Weis and Hochberg, 2000) can be modified to include competitive benefits of defenses, resulting in the opposite prediction (Lischke and Siemens unpublished data).

If defenses are genetically correlated with components of competitiveness then a corollary of the DSB hypothesis is that competition will amplify selection by herbivores on defenses. However, we found that competitive environments can also affect genetic variation in defenses. If the rank order of genotypes for defense levels changes across competitive environments in the field, as we have found in the greenhouse, then this might prevent selection from driving defenses to be higher and less variable in competitive environments as predicted by the DSB hypothesis.

Several hypotheses have been proposed to explain the evolution of plant defenses along a gradient of stressful conditions, such as resource availability, and correlated life history strategies (Feeny, 1976; Rhoades and Cates, 1976; Bryant et al., 1983; Coley et al., 1985; Herms and Mattson, 1992). In essence, these hypotheses attempt to explain the general pattern of slow growth and high levels or numbers of resistance traits associated with plants in stressful environments. According to these hypotheses, limited resources reduce growth rates and the potential to compensate for losses from herbivory, and instead, for various reasons, resistance traits that may be less costly are thought to evolve. The results from our experiments conflict with this general theory in that costs of tolerance to damage were not detectable in a stressful situation and thus some stressful environments may favor the evolution of tolerance defenses. Thus, the DSB hypothesis predicts the evolution of both resistance and tolerance to herbivory in competitive environments where net costs of defenses are reduced.

\section{Acknowledgements}

We thank Mike McDonald, Allison McKeehan, Hollin Moore, Valerie Parrat, and Marianne Suter for help in the greenhouses at ETH and UO. B. McDonald provided greenhouse space at ETH, and D. Dörig (ETH) and M. Trenary (UO) provided technical assistance for the greenhouses. Pilot studies were conducted by D. Siemens in the greenhouse facilities at Northern Arizona University with the technical assistance of Brad Blake and support of the MaxPlanck-Institute for Chemical Ecology, for which he is grateful. Support was provided by postdoctoral fellowship funds to D. Siemens from ETH and UO. 


\section{References}

Adler, F.R. (1999) The balance of terror: an alternative mechanism for competitive trade-offs and its implications for invading species. Am. Nat. 154, 497-509.

Augner, M., Tuomi, J. and Rout, M. (1997) Effects of defoliation on competitive interactions in European white birch. Ecology 78, 2369-2377.

Baldwin, I.T. (1990) Herbivory simulations in ecological research. Trend. Ecol. Evol. 5, 91-93.

Baldwin, I.T. and Hamilton, W. (2000) Jasmonate-induced responses of Nicotiana sylvestris results in fitness costs due to impaired competitive ability for nitrogen. J. Chem. Ecol. 26, 915-952.

Bazzaz, F.A. and Grace, J. (1997) Plant Resource Allocation. Academic Press, San Diego.

Berenbaum, M.R. and Zangerl, A.R. (1999) Coping with life as a menu option: inducible defenses of the wild parsnip. In R. Tollrian and C.D. Harvell (eds) The Ecology and Evolution of Inducible Defenses. Princeton Press, New Jersey, pp. 10-32.

Bergelson, J. (1994a) Changes in fecundity do not predict invasiveness: a model study of transgenic plants. Ecology 75, 249-252.

Bergelson, J. (1994b) The effects of genotype and the environment on costs of resistance in lettuce. Am. Nat. 143, 349-359.

Bergelson, J. and Purrington, C.B. (1996) Surveying patterns in the cost of resistance in plants. Am. Nat. 148, 536-558.

Bergelson, J., Purrington, C.B., Palm, C.J. and López-Gutiérrez, J.-C. (1996) Costs of resistance: a test using transgenic Arabidopsis thaliana. Proc. Royal Soc. London B 263, 1659-1663.

Berrymann, A.A. (1988) Towards a unified theory of plant defence. In W.J. Mattson, J. Levieux and J. Bernard-Dagan (eds) Mechanisms of Woody Plant Defences Against Insects. SpringerVerlag, New York, pp. 39-55.

Bryant, J.P., Chapin III, F.S. and Klein, D.R. (1983) Carbon/nutrient balance of boreal plants in relation to vertebrate herbivory. Oikos 40, 357-368.

Callaway, R.M. and Aschehoug, E.T. (2000) Invasive plants versus their new and old neighbors: a mechanism for exotic invasion. Science 290, 521-523.

Coley, P.D., Bryant, J.P. and Chapin, F.S.I. (1985) Resource availability and plant anti-herbivore defense. Science 230, 895-899.

Darmency, H. and Pérnes, J. (1989) Agronomic performance of a triazine resistant foxtail millet (Setaria italica (L.) Beauv.). Weed Res 29, 147-150.

Feeny, P. (1976) Plant apparency and chemical defense. Recent Adv. Phytochem 10, 1-40.

Fineblum, W.L. and Rausher, M.D. (1995) Tradeoff between resistance and tolerance to herbivore damage in a morning glory. Nature 377, 517-520.

Hamilton, J.G., Zangerl, A.R., DeLucia, E.H. and Berenbaum, M.R. (2001) The carbon-nutrient balance hypothesis: its rise and fall. Ecol. Lett. 4, 86-95.

Herms, D.A. and Mattson, W.J. (1992) The dilemma of plants: to grow or to defend. Quart. Rev. Biol. 67, 283-335.

Hitchcock, A.S. (1951) Manual of the grasses of the United States, [2nd edn revised by Agnes Chase in two volumes. New York: Dover Publications, Inc.]. edition. Department of Agriculture, Agricultural Research Administration, Washington, DC, U.S.

Hochwender, C.G., Marquis, R.J. and Stowe, K.A. (2000) The potential for and constraints on the evolution of compensatory ability in Asclepias syriaca. Ocologia 122, 361-370.

Inderjit (1996) Plant phenolics in allelopathy. Bot. Rev. 62, 186-202.

Jaremo, J., Nilsson, P. and Tuomi, J. (1996) Plant compensatory growth: herbivory or competition? Oikos 77, 238-247.

Jordan, N. (1999) Fitness effects of the triazine resistance mutation in Amaranthus hybridus: relative fitness in maize and soyabean crops. Weed Res. 39, 493-505.

Karban, R. and Baldwin, I.T. (1997) Induced Responses to Herbivory. The University of Chicago Press, Chicago.

Koch, M.A., Haubold, B. and Mitchell-Olds, T. (2000) Comparative evolutionary analysis of chalcone synthase and alcohol dehydrogenase loci in Arabidopsis, Arabis and related genera (Brassicaceae). Mol. Biol. Evol. 17, 1483-1498. 
Mauricio, R. (2000) Natural selection and the joint evolution of tolerance and resistance as plant defenses. Evol. Ecol. 14, 491-507.

Mauricio, R., Rausher, M.D. and Burdick, D.S. (1997) Variation in the defense strategies of plants: are resistance and tolerance mutually exclusive? Ecology 78, 1301-1311.

McKey, D. (1974) Adaptive patterns in alkaloid physiology. Am. Nat. 108, 305-320.

Miller, T.E. (1995) Evolution of Brassica rapa L. (Cruciferae) populations in intra- and interspecific competition. Evolution 49, 1125-1133.

Mitchell-Olds, T. (2001) Arabidopsis thaliana and its wild relatives: a model system for ecology and evolution. Trend. Ecol. Evol. 16, 693-700.

Montgomery, D.C. (1997) Design and Analysis of Experiments, 4th edn. John Wiley and Sons, New York.

Orzack, H. and E. Sober, (eds) (2001) Adaptationism and Optimality. Cambridge University Press, Cambridge.

Pennisi, E. (2000) Arabidopsis kin help keep genetics studies all in the family. Science 290, 2056.

Pilson, D. (2000) The evolution of plant response to herbivory: simultaneously considering resistance and toleranc in Brassica rapa. Evol. Ecol. 14, 457-489.

Purrington, C.B. (2000) Costs of resistance. Curr. Opin. Plant Biol. 3, 305-308.

Purrington, C.B. and Bergelson, J. (1997) Fitness consequences of genetically engineered herbicide and antibiotic resistance in Arabidopsis thaliana. Genetics 145, 807-814.

Rausher, M. (1996) Genetic analysis of coevolution between plants and their natural enemies. Trend. Genet. 12, 212-217.

Reboud, X. and Till-Bottraud, I. (1991) The cost of herbicide resistance measured by a competition experiment. Theor. Appl. Genet. 82, 690-696.

Rhoades, D.F. (1979) Evolution of plant chemical defenses against herbivory. In G.A. Rosenthal and D.H. Janzen (eds) Herbivores: Their Interaction with Secondary Plant Metabolites. Academic Press, New York, pp. 3-54.

Rhoades, D.F. and Cates R.G. (1976) Towards a general theory of plant antiherbivore chemistry. Recent Adv. Phytochem. 10, 168-213.

Rollins, R.C. (1993) The Cruciferae of North America: Systematics of The Mustard Family From The Arctic To Panama. Stanford University Press, Stanford.

Roy, B.A. (1995) The breeding systems of six species of Arabis. Am. J. Bot. 82, 869-877.

Roy, B.A. and Kirchner, J.W. (2000) Evolutionary dynamics of pathogen resistance and tolerance. Evolution 54, 51-63.

Shelton, A.M., Cooley, M.K., Kroening, K., Wilsey, W.T. and Eigenbrode, S.D. (1990) Comparative analysis of two rearing procedures for diamondback moth (Lepidoptera: Plutellidae). J. Entomol. Sci. 26, 17-26.

Siemens, D.H. and Mitchell-Olds, T. (1996) Glucosinolates and herbivory by specialists (Coleoptera: Chyrsomelidae, Lepidoptera: Plutellidae): consequences of concentration and induced resistance. Environ. Entomol. 25, 1344-1353.

Siemens, D.H. and Mitchell-Olds, T. (1998) Evolution of pest-induced defenses in Brassica plants: tests of theory. Ecology 79, 632-646.

Siemens, D.H., Garner, S.H., Mitchell-Olds, T. and Callaway, R.M. (2002) Cost of defense in the context of plant competition: Brassica rapa may grow and defend. Ecology 83, 505-517.

Simms, E.L. (1992) Costs of plant resistance to herbivory. In R.S. Fritz and E.L. Simms (eds) Plant Resistance to Herbivores and Pathogens: Ecology, Evolution, and Genetics. University of Chicago Press, Chicago, pp. 392-425.

Simms, E.L. (2000) Defining tolerance as a norm of reaction. Evol. Ecol. 14, 563-570.

Simms, E.L. and Rausher, M.D. (1987) Costs and benefits of plant resistance to herbivory. Am. Nat. 130, 570-581.

Simms, E.L. and Rauscher, M.D. (1992) Uses of quantitative genetics for studying the evolution of plant resistance. In: R.S. Fritz and E.L. Simms (eds) Plant Resistance to Herbivores and Pathogens. University of Chicago Press, Chicago, pp. 42-68.

Stotz, H.U., Kroymann, J. and Mitchell-Olds, T. (1999) Plant-insect interactions. Curr. Opin. Plant Biol. 2, 268-272. 
Stotz, H.U., Pittendrigh, B.R., Kroymann, J., Weniger, K., Fritsche, J., Bauke, A. and MitchellOlds, T. (2000) Induced plant defenses against chewing insects: ethylene signaling reduces resistance of Arabidopsis against Spodoptera littoralis. Plant Physiology in review.

Stowe, K.A. (1998) Experimental evolution of resistance in Brassica rapa: correlated response of tolerance in lines selected for glucosinolate content. Evolution 52, 703-712.

Stowe, K.A., Marquis, R.J., Hochwender, C.G. and Simms, E.L. (2000) The evolutionary ecology of tolerance to consumer damage. Ann. Rev. Ecol. Syst. 31, 565-595.

Strauss, S.Y. and Agrawal, A.A. (1999) The ecology and evolution of plant tolerance to herbivory. Trend. Ecol. Evol. 14, 179-185.

Strauss, S.Y., Rudgers, J.A., Lau, J.A. and Irwin, R.E. (2002) Direct and ecological costs of resistance to herbivory. Trend. Ecol. Evol. 17, 278-285.

Strauss, S.Y., Siemens, D.H., Decher, M.B. and Mitchell-Olds, T. (1999) Ecological costs of plant resistance to herbivores in the currency of pollination. Evolution 53, 1105-1113.

Tiffin, P. (1999) Are tolerance, avoidance, and antibiosis evolutionary and ecologically equivalent responses of plants to herbivores? Am. Nat. 155, 128-138.

Tiffin, P. and Inouye, B.D. (2000) Measuring tolerance to herbivory: accuracy and precision of estimates made using natural versus imposed damage. Evolution 54, 1024-1029.

Tiffin, P. and Rausher, M.D. (1999) Genetic constraints and selection acting on tolerance to herbivory in the common morning glory Ipomea purpurea. Am. Nat. 154, 700-716.

van Dam, N.M. and Baldwin, I.T. (1998) Costs of jasmonate-induced responses in plants competing for limited resources. Ecol. Lett. 1, 30-33.

Weis, A.E. and Campbell, D.R. (1991) Plant genotype: a variable factor in animal-plant interactions. In M.D. Hunter, T. Ohgushi and P.W. Price (eds) Effects of Resource Distribution on Animal-Plant Interactions. Academic Press, Orlando.

Weis, A.E. and Hochberg, M.E. (2000) The diverse effects of intraspecific competition on the selective advantage to resistance: a model and its predictions. Am. Nat. 156, 276-292.

Weis, A.E., Simms, E. and Hochberg, M.E. (2000) Will plant vigor and tolerance be genetically correlated? Effects of intrinsic growth rate and self-limitation on regrowth. Evol. Ecol. 14, 331352.

Williams, M.M.I., Jordan, N. and Yerkes, C. (1995) The fitness cost of triazine resistance in jumson weed (Datura stramonium L.). Am. Midl. Nat. 133, 131-137.

Zangerl, A.R. and Bazzaz, F.A. (1992) Theory and pattern in plant defense allocation. In R.S. Fritz and E.L. Simms (eds) Plant Resistance to Herbivores and Pathogens: Ecology, Evolution, and Genetics. Chicago Press, Chicago.

Zar, J.H. (1996) Biostatistical Analysis. 3rd edn Prentice Hall, Upper Saddle River, New Jersey. 